\title{
Comparison between anterior cervical discectomy with fusion by polyetheretherketone cages and tricortical iliac crest graft for the treatment of cervical prolapsed intervertebral disc
}

\author{
Md. Anowarul Islam, Md. Masud Rana, Md. Fahad Goni and Md. Naimur Rahman
}

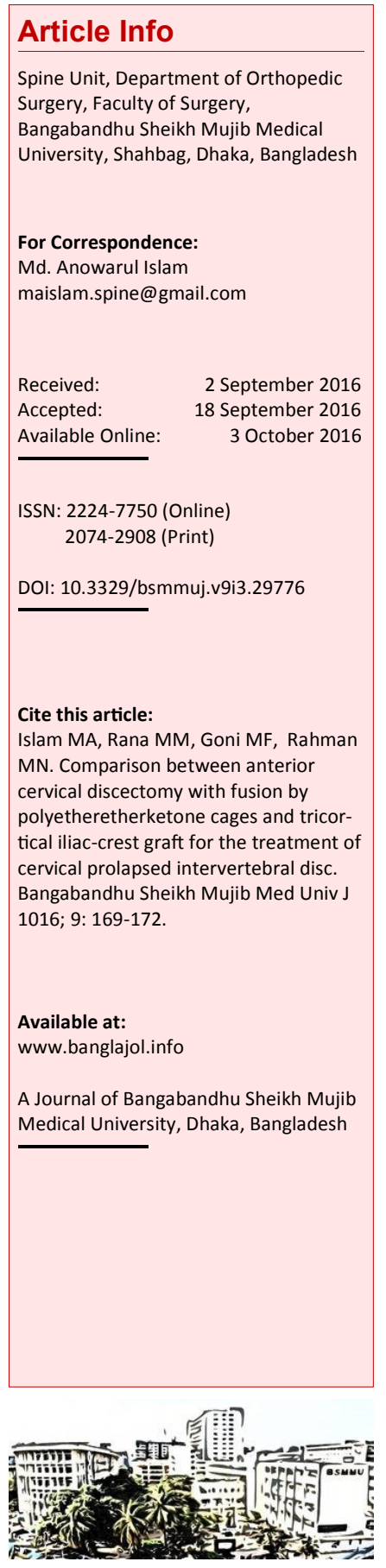

\section{Abstract}

Anterior cervical discectomy and fusion is effective surgical modality in the treatment of cervical prolapsed intervertebral disc, radiculopathy and myelopathy. Aims of our study is to evaluate fusion of cervical spine by iliac crest graft (ICG) with plating and polyetheretherketone (PEEK) cage with bone graft, also assess the donor site morbidity. Thirty patients (male 16; female 14) with mean age $46 \pm 9.2$ years and were distributed into two treatment groups (PEEK cage group and ICG group). We assess the patients clinically for myelopathy and functional outcome by Nurick scale and Odom's criteria respectively and neck and arm pain by Visual Analogue Scale (VAS). Eighteen patients were operated for single level discectomy and fusion by either ICG or PEEK cages and twelve patients for two levels. After surgery follow up was 2 years and better postoperative score which was assessed by Nurick scale, Odoms criteria and VAS score. Total patients $14(93 \%)$ were graded excellent in the PEEK cage group compared to 13 patients $(86 \%)$ in the ICG group. Statistically it was not significant between two groups and $\mathrm{p}$ value was $<0.35$. Difference was significant in VAS score after 24 months with more reduction of pain in PEEK cage group. Fusion occurred in 13 patients (86\%) of the PEEK cage group and 14 patient $(93 \%)$ of the ICG group. Result showed more fusion rate in ICG group and less donor site morbidity in PEEK group.

\section{Introduction}

Interbody fusion provides spine surgeon the ability to limit abnormal painful motion in the spine. Recent treatment modality declares that fusion is the ideal treatment in cervical prolapsed intervertibral disc. Interbody fusion rate is about $92 \%$ by anterior cervical discectomy and fusion (ACDF). 1 ACDF is indicated for radiculopathy, myelopathy and fracture dislocation of spine. 2

Several modalities of surgery for performing ACDF such as Cloward technique, Smith Robinson technique, Bailey/Badgley technique. $\underline{1,3}$ Auto and allo bone graft along with different cages are used for fusion. Various materials have been used for fusion too, as iliac crest graft (ICG),,$\underline{\mathbf{u}}$ allograft, $\underline{\mathbf{1}}$ cement, $\mathbf{5}$ and bone morphogenetic proteins. 6 If the graft is used without any cage, it could be collapsed, extruded and there could be pseudoarthosis. To achieve further stability plate with screw is used along with bone graft.

Chance of nonunion is up to $25 \%$ in a single level and up to $60 \%$ in multilevel surgery. So, fusion is influenced by number of level of surgery and types of graft and cage used. In this study, we have tried to compare the out- come between ACDF surgery with polyetheretherketone (PEEK) cage and tricortical bone graft.

\section{Materials and Methods}

Thirty consecutive patients referred to the Department of Orthopaedic Surgery from July 2011 to June 2016 were recruited for the study purpose and randomized into two groups: one group for ICG and another for PEEK cage. Patients were distributed by a lottery system. All the patients were treated conservatively in the form of medicine and physiotherapy. Variables included were age, sex, symptom duration before surgery, radicular and neck pain, myelopathy, and paresis were documented on the day before surgery. The VAS score was used to evaluate pain status. Pre- and postoperative Nurick scale? was used to assess the myelopathy and Odom's 8 criteria for the functional outcome.

Recurrent cervical disc prolapsed, previous disc surgery and infection were excluded from the study. During surgery the following parameters were included: Number of fusion levels (single - or double-levels), fusion of level (C3/C4; C4/ 
C5; C5/C6; or C6/7) and type of fusion (PEEK cage or ICG). Patient follow-up was done clinically and by X-ray at $8^{\text {th }}, 12^{\text {th }}, 24^{\text {th }}$ weeks and 12,24 month. Each complication after operation was recorded

Additional plate fixation was used in ICG. We followed Smith Robinson technique. Under G/A draping sheet were placed under the scapula to achieve extension. After opening muscle plane retracted to reach the vertebra. The interest levels were identified and verified using C-arm. Removal of the disc was done by curette and Kerrison forcep. Special protection was taken to prevent neural and vertebral body injury. Both the endplate were curated before insertion of bone graft or cage to facilitate fusion. After excision of PLL we decompressed the nerve root by removal of the extruded disc. After descectomy and nerve root decompression graft with the cage was introduced. We used 12Fr drain tube and cervical collar for 6 weeks postoperatively in both groups. After operation we kept the patient nothing per oral for 24 hours then we allowed sips of water and diet subsequently. We advised avoiding pillow for 4 weeks after surgery. The patient returned to normal daily activity after 6 weeks but to avoid heavy weight lifting.

Postoperative $\mathrm{X}$-ray was taken in the supine position and $8^{\text {th }}, 12^{\text {th }}, 24^{\text {th }}$ weeks and 12,24 months after surgery.

We assess the postoperative kyphotic angle by measuring the angle between the posterior borders of two adjacent vertebral bodies. If the interbody angle is greater than 2 degrees on dynamic X-ray, the nonunion is declared.

\section{Database and statistical analysis}

We performed statistical analysis by SPSS version 22. We measured the mean \pm standard deviation (SD) for quantitative data and qualitative data was

\begin{tabular}{|c|c|c|c|}
\hline \multicolumn{4}{|c|}{ Table I } \\
\hline \multicolumn{4}{|c|}{ Difference between two groups } \\
\hline Types of surgery & Cage (PEEK) & ICG & Total \\
\hline Number of patient & $\begin{array}{r}15 \\
(50)\end{array}$ & $\begin{array}{r}15 \\
(50)\end{array}$ & $(100)$ \\
\hline $\begin{array}{l}\text { Sex: } \\
\qquad \text { Male }\end{array}$ & $\begin{array}{r}9 \\
(56.2)\end{array}$ & $\begin{array}{r}7 \\
(43.7)\end{array}$ & $\begin{array}{r}16 \\
(100)\end{array}$ \\
\hline Female & $\begin{array}{r}6 \\
(42.8)\end{array}$ & $\begin{array}{r}8 \\
(57.1)\end{array}$ & $\begin{array}{r}14 \\
(100)\end{array}$ \\
\hline Fusion after 24 months & $\begin{array}{r}13 \\
(86)\end{array}$ & $\begin{array}{r}14 \\
(93.3)\end{array}$ & \\
\hline Outcome (excellent) & $\begin{array}{r}14 \\
(93)\end{array}$ & $\begin{array}{r}13 \\
(86)\end{array}$ & \\
\hline
\end{tabular}

measured by number. Chi-squared test was used to test the difference between proportion. Fisher's exact test was done if required. Student's t-test was applied to test mean differences between groups. We use paired t-test for comparison of pre- and post-treatment. We use $95 \%$ of the confidence interval for determination of statistical significance. If the $\mathrm{p}$ value was $<0.05$, student's t-test was used.

\section{Results}

The study included 30 patients. We operated eighteen patients for single level discectomy and fusion by either ICG or PEEK cages (Figure 1 and 2) and twelve patients were operated for doublelevels. Among 30 patients $16(53.3 \%)$ were males and $14(47.8 \%)$ were females. Patients age ranged from 35-59 years, a mean \pm SD $46 \pm 9.2$. Table I show the differences between two groups.

There were 7 patients (23.3\%) with radiculopathy, 9 patients (30\%) with myelopathy, and 13 patients $(43.3 \%)$ with radiculomyelopathy. Regarding the levels operated, there were 4 C3-4 levels, 8 C4-5 levels, 12 C5-6 levels, and 6 C6-7 levels. Patients were followed-up for a period of 6 months.

The significant post-operative improvement was recorded after 24 months by VAS and Nurick scale. According to Odom criteria, we graded 14 patients $(93.3 \%)$ excellent-good in the cage group in comparison to 13 patients $(86.6 \%)$ in the bone graft group. We graded no patient as poor. The relation was not statistically significant between the two group as $p<0.30$. There was no difference in improvement of VAS scores between two groups. There were some transient complications; dysphagia is reported in 4 patients (13.3\%) and improved after 3 weeks, SSI in graft site reported in 1 patient $(3.3 \%)$.

Fusion occurred in $13 / 15$ patients (86\%) segments of the PEEK group, while it was 14/15 (93.3\%) of the ICG group segments. Persistent pain was noted in the non-fusion group.

\section{Discussion}

Interbody fusion by bone graft provide stability and achieve disc height and reduced radicular pain. If we do only discectomy there symptom get worse due to loss of disc height, canal narrowing and compression on neural structure again. Reduced cervical lordosis results in degenerative change over the adjacent segment.

Fusion by a cage with bone graft provides primary stability in degenerative spine.

In this study, fusion occurred in 13 patients $(86 \%)$ 


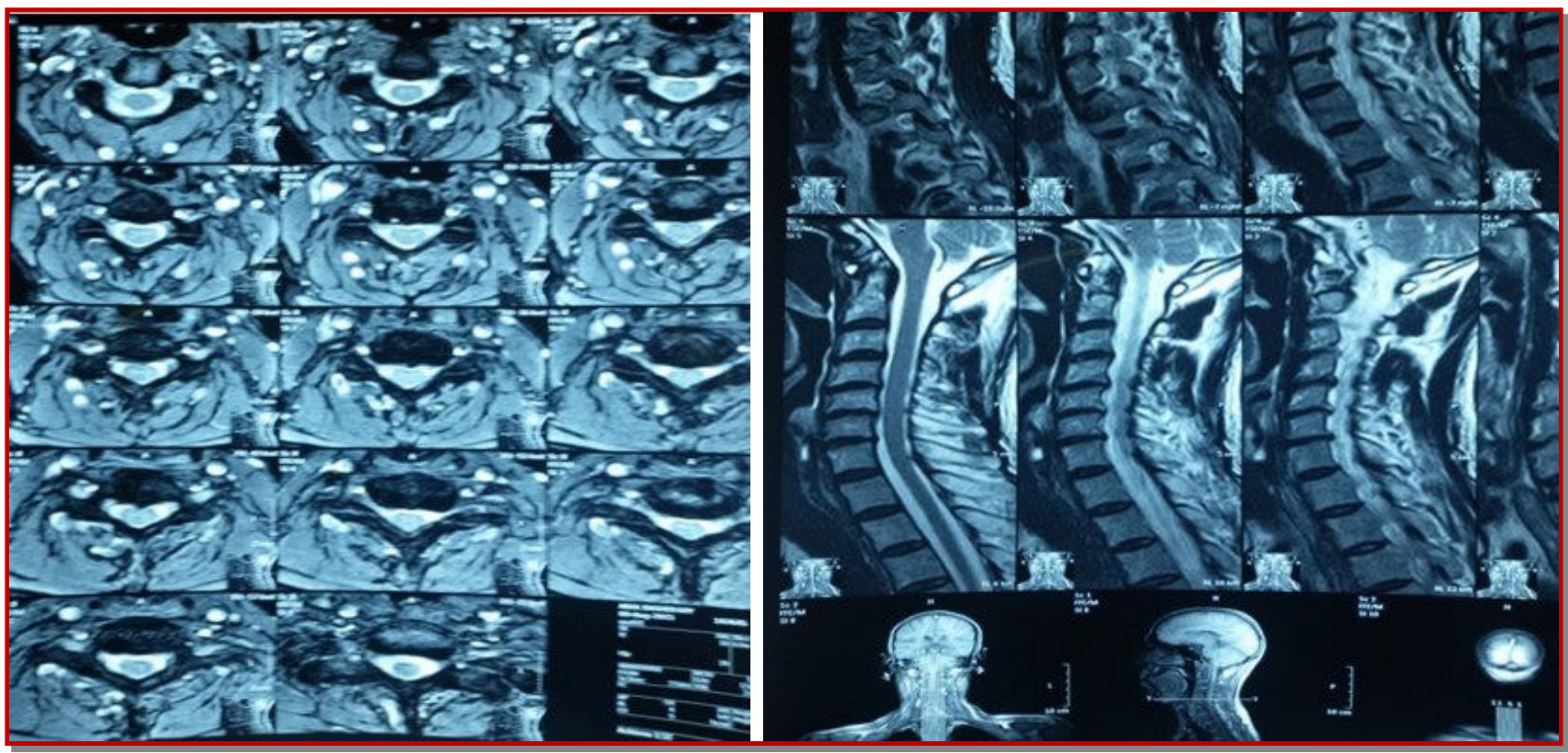

Figure 1: Preoperative MRI axial (left photograph) and sagital (right photograph) views

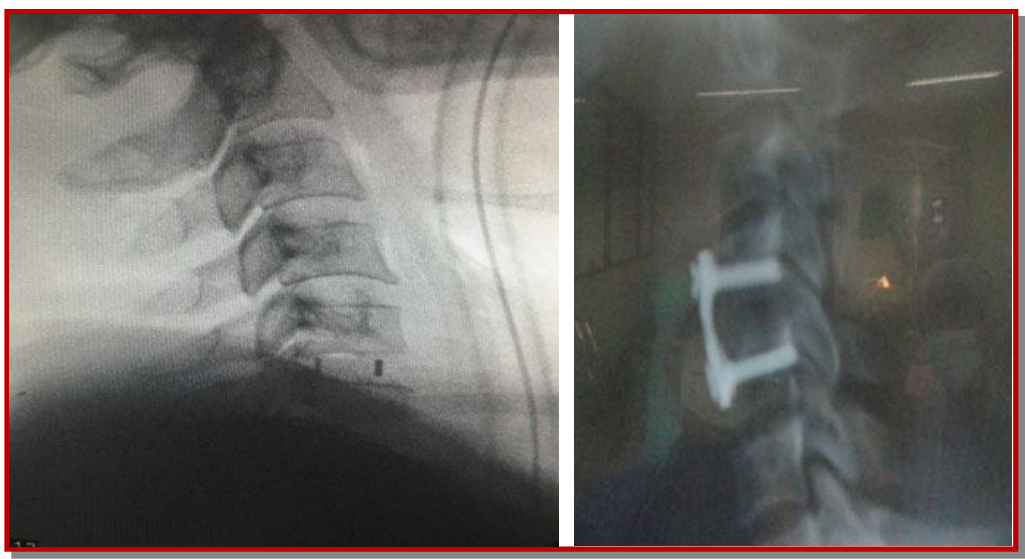

Figure 2: Postoperative X-ray of PEEK cage (left) and ICG with platting (right)

are in PEEK group.

Kim et al9 showed $30 \%$ bone graft and all had achieved fusion at 6-12 months. In the case of bone graft with plating, one study shows complete fusion occurred in $100 \%$ of single-level and other study show $98 \%$ of double-level procedures. In our series, there are $93.3 \%$ fusion in ICG with plating.

The literature also reports a consistent $1-12 \%$ nonfusion for anterior discectomy its similar in our study $10 \%$.

Hacker et al $\underline{10}$ compared cage with bone graft and bone graft with plating, and found there is no significant difference in clinical outcome between the two groups its also has similarity with our study.

This study found that fusion is higher in ICG group than PEEK group with bone graft. Many surgeon prefer cage with bone graft than ICG due to less donor site morbidity.

So far, there is no significant difference in the fusion rate between ICG and cage. Some prefer ICG as its high fusion rate and low cost. Cage fusion also provides favorable outcome but one should be careful about post operative cage subsidence.

\section{Conclusion}

$\mathrm{ACDF}$ is the ideal technique in the treatment of cervical disc disease with excellent functional outcome, good fusion which could be achieve by either ICG or cage. ICG still consider as effective in the treatment of cervical myelopathy, radiculopathy. PEEK cage could be as effective alternative with good fusion and less donor morbidity.

\section{References}

1. Yang JJ, Yu CH, Chang BS, Yeom JS, Lee JH, Lee $\mathrm{CK}$. Subsidence and nonunion after anterior cervical interbody fusion using a stand-alone polyetheretherketone (PEEK) cage. Clin Orthop Surg. 2011; 3: 16-23.

2. Lied B, Roenning PA, Sundseth J, Helseth E. Anterior cervical discectomy with fusion in patient with cervical degeneration a prospective outcome study of 258 patients (181 fused with autologous bone graft and 77 fused with a PEEK cage. BMC Surg. 2010; 10: 10. 
3. Cloward RB. The anterior approach for removal of ruptured cervical disc. J Neurosurg. 1956; 15: 60217.

4. Chau AMT, Mobbs RJ. Bone graft substitutes in anterior cervical discectomy and fusion. Eur Spine J. 2009; 18: 449-64.

5. Eck KR, Lenke LG, Bridwell KH, Gilula LA, Lashgari CJ, Riew KD. Radiographic assessment of anterior titanium mesh cages. J Spinal Disord. 2000; 13: 501-10.

6. Siddiqui AA, Jackowski A. Cage versus tricortical graft for cervical interbody fusion: A prospective randomised study. J Bone Joint Surg. 2003; 85: 1019-25.
7. Nurick S. The pathogenesis of the spinal cord disorder associated with cervical spondylosis. Brain 1972; 95: 87-100.

8. Odom GL, Finney W, Woodhall B. Cervical disc lesions. JAMA. 1958; 166: 23-28.

9. Kim P, Wakai S, Matsuo S, Mriyama T and Kirino T. Bisegmental cervical interbody fusion using hydroxyapatite implants: Surgical results and long-term observation in 70 cases. J Neurosurg. 1998; 88: 21-27.

10. Hacker RJ, Cauthen JC, Gilbert TJ, Griffith SL. A prospective multicentre clinical evaluation of an anterior fusion cage. Spine 2000; 20: 2646-54. 